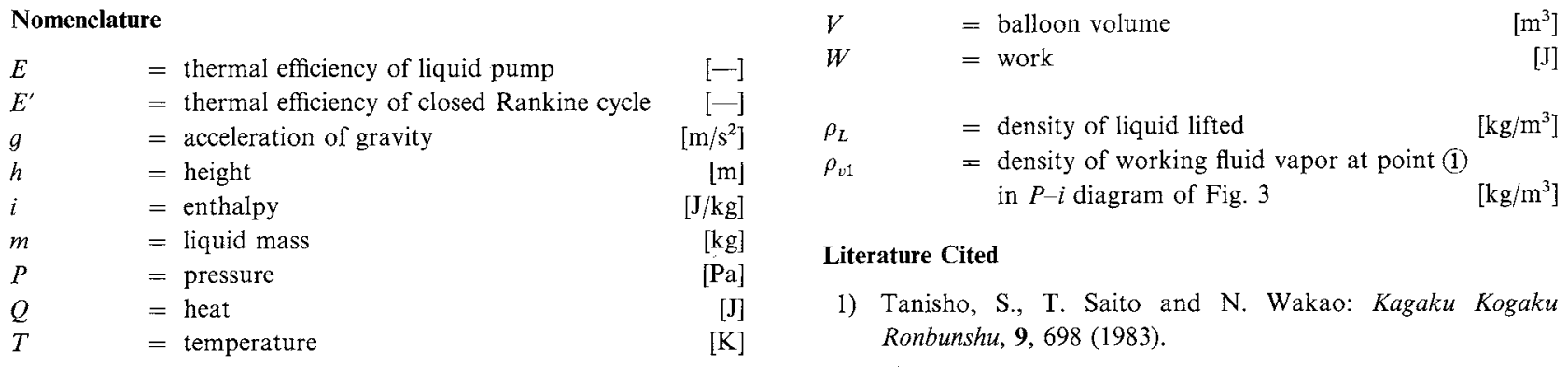

\title{
GAS ABSORPTION IN AN AERATED MIXING VESSEL WITH MULTI-STAGE IMPELLERS
}

\author{
MASABUmi NISHIKAWA, SHIGERU NISHIOKA AND TAKASHI KAYAMA \\ Department of Nuclear Engineering, Kyushu University, Fukuoka 812
}

Key Words: Aerated Mixing Vessel, Gas Absorption, Two-Region Model, Multistage Impellers, Turbine,
Paddle

Aerated mixing vessels with multistage impellers are often used in the biological and chemical industries. In many cases, $k_{L} a$ has been used as the scale-up standard as reported by Fukuda et al. ${ }^{1)}$ and Tuffile and Pinho, ${ }^{6)}$ though the correlative equations for $k_{L} a$ in the literature are limited and, very often, contradictory. Nishikawa et al. $^{2-4)}$ have proposed a dimensionless equation to estimate $k_{L} a$ for a wide range of operational conditions by using the tworegion model where the coexistence of the bubblingcontrolling condition region and the agitationcontrolling condition region in an aerated mixing vessel is assumed.

$k_{L} a$ in an aerated mixing vessel with multistage impellers is discussed in this paper in relation to the two-region model.

\section{Experimental}

$k_{\mathrm{L}} a$ was measured by tracing the change of dissolved oxygen concentration in sugar solutions with time, using an oxygen electrode. Details of the experimental procedures were shown in previous papers by the present authors. ${ }^{2,3)}$

Physical properties of sugar solutions used in this study are listed in Table 1.

Received December 5, 1983. Correspondence concerning this article should be addressed to M. Nishikawa. S. Nishioka and T. Kayama are now with Satake Chemical Equipment Mfg., Ltd., Moriguchi 570.

\section{Results and Discussion}

The dimensionless equation for $k_{L} a$ in an aerated mixing vessel with a turbine-type impeller is shown as follows, using the two-region model. ${ }^{3)}$

$$
\begin{aligned}
& \left(k_{L} a D^{2} / D_{L}\right) \\
& =0.115\left(d^{2} n \rho / \mu\right)^{1.5}\left(\mu / \rho D_{L}\right)^{0.5}\left(\mu u_{g} / \sigma\right)^{0.5} \\
& \quad \times\left(d n^{2} / g\right)^{0.367}\left(n d / u_{g}\right)^{0.167}(d / D)^{0.4} N_{p}^{0.8} \\
& +0.112 P_{a v} /\left(P_{g v} / N_{p}+P_{a v}\right)\left(u_{g} / \sqrt{g D}\right) \\
& \quad \times\left(\mu / \rho D_{L}\right)^{0.5}\left(g D^{2} \rho / \sigma\right)^{0.66}\left(g D^{3} \rho^{2} / \mu^{2}\right)^{0.42}
\end{aligned}
$$

where $P_{g v}$ and $P_{a v}$ are agitation power per unit mass of liquid and aeration power per unit mass of liquid, respectively. (Exponent of $\mathbf{- 2}$ for the $(d / D)$ term in Eqs. (13) and (28) in the previous paper ${ }^{3)}$ is incorrect.)

\begin{tabular}{|c|c|c|c|}
\hline & $10 \%$ sol. & $30 \%$ sol. & $50 \%$ sol. \\
\hline$\rho\left[\mathrm{g} / \mathrm{cm}^{3}\right]$ & 1.04 & 1.13 & 1.20 \\
\hline$\sigma\left[\mathrm{g} / \mathrm{cm}^{2}\right]$ & 71 & 71 & 71 \\
\hline$D_{L}\left[\mathrm{~cm}^{2} / \mathrm{s}\right]$ & $1.1 \times 10^{-5}$ & $1.2 \times 10^{-5}$ & $3.0 \times 10^{-6}$ \\
\hline$\mu[\mathrm{g} / \mathrm{cm} \cdot \mathrm{s}]$ & 0.015 & 0.025 & 0.18 \\
\hline
\end{tabular}

Effects of impeller clearance on $k_{L} a$ for two-stage impellers are compared with the estimated values in Table 2, where agitation power is obtained from the

Table 1. Physical properties of sugar solutions 
Table 2. Effect of impeller clearance on $k_{L} a(D=30 \mathrm{~cm}$, $H / D=2, d / D=1 / 2, b / D=0.1, n_{p}=6, n_{B}=4, n=4.17 \mathrm{~s}^{-1}, u_{g}=$ $1.3 \mathrm{~cm} / \mathrm{s}, 30 \%$ sugar solution)

\begin{tabular}{|c|c|c|c|c|c|}
\hline \multirow{2}{*}{$c_{1}$} & \multirow{2}{*}{$c_{2}$} & \multicolumn{2}{|c|}{ Turbine-type } & \multicolumn{2}{|c|}{ Paddle-type } \\
\hline & & $\left(k_{L} a\right)_{\text {obs }}$ & $\left(k_{L} a\right)_{\mathrm{cal}}$ & $\left(k_{L} a\right)_{\circ \mathrm{r}}$ & $\left(k_{L} a\right)_{\text {cal }}$ \\
\hline $10 \mathrm{~cm}$ & $50 \mathrm{~cm}$ & $0.0122 s^{-1}$ & $0.0118 \mathrm{~s}^{-1}$ & $0.0131 \mathrm{~s}^{-1}$ & $0.0135 \mathrm{~s}^{-1}$ \\
\hline 10 & 40 & 0.0127 & 0.0134 & 0.0138 & 0.0146 \\
\hline 10 & 22 & & 0.0110 & & 0.0118 \\
\hline 10 & 17.5 & 0.0103 & 0.0095 & 0.0115 & 0.0124 \\
\hline 10 & 15 & & 0.0080 & 0.0138 & 0.0146 \\
\hline 10 & - & 0.0071 & 0.0072 & 0.0083 & 0.0087 \\
\hline
\end{tabular}

correlation reported by Nishikawa et al..$^{5)}$ As can be seen from this table, the two-region model can be applied to multistage impellers because the estimated values show good agreement with the observed values. A similar conclusion can also be obtained from Fig. 1, where observed $k_{L} a$ values are compared with estimated values from Eq. (1) for cases when impeller speeds are changed.

Change of impeller power with impeller clearance will have the effect on $k_{L} a$ shown in Fig. 2, where change of $k_{L} a$ with impeller clearance under the agitation-controlling condition is estimated for turbine and paddle-type impellers. This figure indicates that addition of the second turbine can increase $k_{L} a$ by $74 \%$ at most, though no increase is expected if the second turbine is not properly positioned.

In the case of a paddle-type impeller, $68 \%$ increase can be expected by addition of the second impeller, though improper positioning gives only a $37 \%$ increase. It was reported by the present authors ${ }^{3)}$ that the paddle-type impeller gives larger $k_{L} a$ than the turbine at higher liquid viscosity or smaller $P_{g v}$. A report by Yagi and Yoshida $a^{7}$ implies that the paddle may be better for liquids with large elasticity. Figure 2 also implies that the multistage paddle could be better when there is insufficient impeller clearance.

The present authors recommend the following impeller clearance from the viewpoint of $k_{L} a$.

$\Delta c / d>1.5 \quad$ for turbine-type

$\Delta c / d>1.6$ or $\Delta c / d<0.1 \quad$ for paddle-type

The effect of impeller clearance on $k_{L} a$ becomes smaller with decrease of agitation power, $P_{g v}$, as is evaluated in Fig. 3, because the bubbling-controlling condition part in the aerated mixing vessel increases. Accordingly, arguments about impeller configurations are meaningless when the vessel condition is bubbling-controlling.

\section{Conclusion}

1) $k_{L} a$ in a mixing vessel with multistage impellers can also be correlated by the expression for a vessel

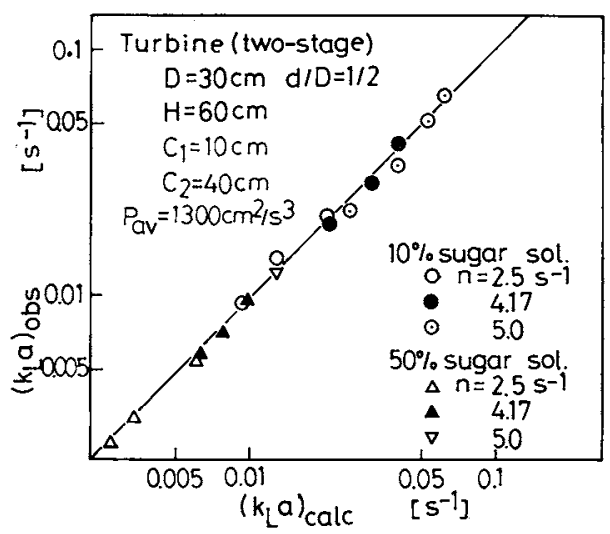

Fig. 1. Comparison of observed $k_{L} a$ with estimated values for aerated vessel with multistage impellers.

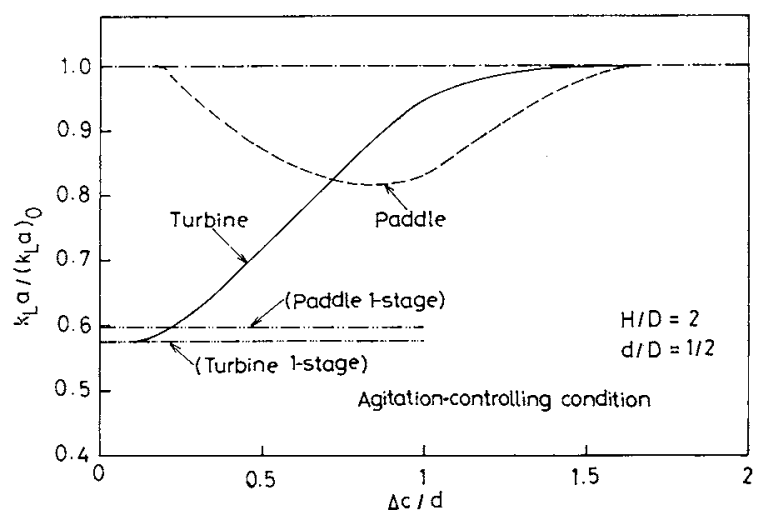

Fig. 2. Effect of clearance on $k_{L} a$ under agitation-controlling condition

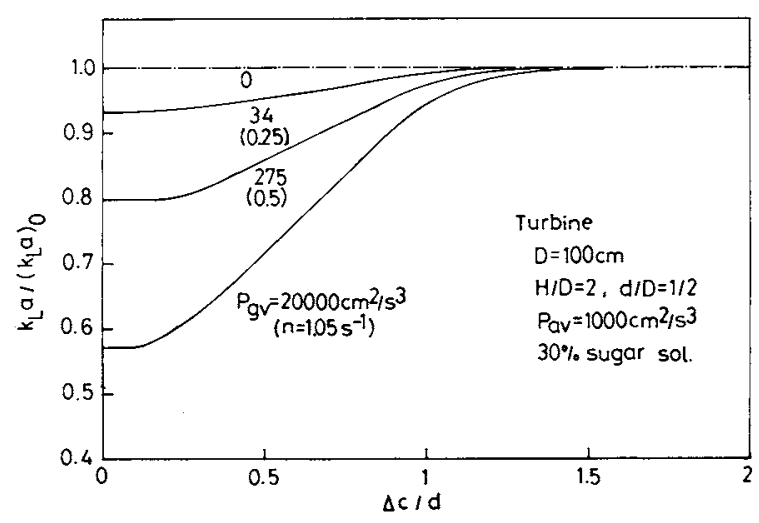

Fig. 3. Effect of clearance when aeration becomes comparatively strong.

with an impeller, using the two-region model.

2) The proper impeller clearance is required to obtain an effective increase of $k_{L} a$ by addition of a impeller.

$\begin{array}{lll}\text { Nomenclature } & \\ b & =\text { blade width of impeller } & {[\mathrm{cm}]} \\ c & =\text { impeller level from vessel bottom } & {[\mathrm{cm}]} \\ c_{1} & =\text { first-stage impeller level from vessel } & \\ & \text { bottom } & {[\mathrm{cm}]}\end{array}$




$\begin{array}{llr}c_{2} & =\text { second-stage impeller level from vessel } & \\ & \text { bottom } & {[\mathrm{cm}]} \\ \Delta c & =\text { clearance between impellers } & {[\mathrm{cm}]} \\ D & =\text { vessel diameter } & {[\mathrm{cm}]} \\ D_{L} & =\text { liquid-phase diffusivity } & {\left[\mathrm{cm}{ }^{2} / \mathrm{s}\right]} \\ d & =\text { impeller diameter } & {[\mathrm{cm}]} \\ g & =\text { gravitational acceleration } & {\left[\mathrm{cm} / \mathrm{s}^{2}\right]} \\ H & =\text { liquid height in vessel } & {[\mathrm{cm}]} \\ k_{L} a & =\text { capacity coefficient in gas absorption } & {\left[\mathrm{s}^{-1}\right]} \\ \left(k_{L} a\right)_{0} & =k_{L} a \text { obtained in vessel with single-stage } & \\ & \text { impeller where } H / D=1 & {\left[\mathrm{~s}^{-1}\right]} \\ N_{p} & =\text { power number } & {[-]} \\ n & =\text { impeller speed } & {\left[\mathrm{s}^{-1}\right]} \\ n_{B} & =\text { number of baffe plates } & {[-]} \\ n_{p} & =\text { number of impeller blades } & {[-]} \\ P_{a v} & =\text { aeration power per unit mass of liquid } & {\left[\mathrm{cm}^{2} / \mathrm{s}^{3}\right]} \\ P_{g v} & =\text { agitation power per unit mass of liquid } & {\left[\mathrm{cm}^{2} / \mathrm{s}^{3}\right]} \\ & =\text { liquid viscosity } & {\left[\mathrm{g} / \mathrm{cm}^{2} \cdot \mathrm{s}\right]} \\ & =\text { liquid density } & {\left[\mathrm{g} / \mathrm{cm}^{3}\right]}\end{array}$

\title{
Literature Cited
}

1) Fukuda, H., Y. Sumino and T. Kanzaki: J. Ferment. Technol., 46, 829 (1968).

2) Nishikawa, M., M. Nakamura, H. Yagi and K. Hashimoto: $J$. Chem. Eng. Japan, 14, 219 (1981).

3) Nishikawa, M., M. Nakamura and K. Hashimoto: J. Chem. Eng. Japan, 14, 227 (1981).

4) Nishikawa, M., S. Nishioka and F. Fujieda: Kagaku Kogaku Ronbunshu, 9, 76 (1983).

5) Nishikawa, M., K. Ashiwake, N. Hashimoto and S. Nagata: Kagaku Kogaku Ronbunshu, 2, 426 (1976).

6) Tuffile, C. M. and F. Pinho: Biotech. and Bioeng., 12, 849 (1970).

7) Yagi, H. and F. Yoshida: Ind. Eng. Chem., Process Des. Dev., 14, 488 (1975).

\section{SECOND VIRIAL COEFFICIENT OF ETHANE AT 423.15 K AND PREDICTION OF SECOND VIRIAL COEFFICIENTS FOR NORMAL ALKANES}

\author{
KAZUNARI OHGAKI, YOICHI KANO AND TAKASHI KATAYAMA \\ Department of Chemical Engineering, Faculty of Engineering Science, Osaka University, Toyonaka 560
}

\begin{abstract}
Key Words: Physical Property, Second Virial Coefficient, Ethane, Normal Alkane, Molecular Potential
Model
\end{abstract}

In a previous paper, ${ }^{7)}$ a simple potential model based on a group-contribution concept was proposed for predicting second virial coefficients of linear symmetric molecules. At that time, fundamental group parameters of the methyl group for the model were determined tentatively from literature values of second virial coefficients for ethane.

In the present study, the second virial coefficient of ethane at $423.15 \mathrm{~K}$ was measured by the Burnett method. Thereafter, by use of the value at $423.15 \mathrm{~K}$ and that at $298.15 \mathrm{~K}$ obtained previously, ${ }^{4)}$ the group parameters of the methyl group for the model have been redetermined.

\section{Second Virial Coefficient of Ethane at $423.15 \mathrm{~K}$}

The experimental apparatus and procedures used in the present study were identical to those described in a previous paper. ${ }^{6)}$

Research-grade ethane supplied by Phillips

Received January 4, 1984. Correspondence concerning this article should be addressed to T. Katayama. Y. Kano is now at Sumitomo Metal Industries, Ltd., Amagasaki.
Petroleum Co. had a specified minimum purity of $99.99 \mathrm{~mol} \%$ and was used without further purification in the experiments.

The method of data reduction based on the virial equation of Berlin-form is the same as that used in a previous paper. ${ }^{4)}$

The second virial coefficient of ethane obtained in the present study is compared with literature values in Table 1. The values of Dymond-Smith ${ }^{2}$ and of Douslin-Harrison ${ }^{1)}$ are larger than the value obtained in the present study by about $2-3 \mathrm{~cm}^{3} \cdot \mathrm{mol}^{-1}$. The value of Eubank-Mansoorian ${ }^{3)}$ is in good agreement within experimental uncertainty. On the other hand, the prediction result of Tsonopoulos ${ }^{8)}$ is smaller by about $2 \mathrm{~cm}^{3} \cdot \mathrm{mol}^{-1}$ in absolute terms.

\section{Prediction of Second Virial Coefficients for Normal Alkanes}

A simple potential model (abbreviated OK model hereafter), proposed for predicting second virial coefficients of linear symmetric molecules in the previous 